r ScIDioc

\section{Generation and characterization of induced pluripotent stem cells in domestic Asian water buffalo (Bubalus bubalis)}

\section{International Journal of Stem Cell Research and Transplantation (IJST) ISSN 2328-3548}

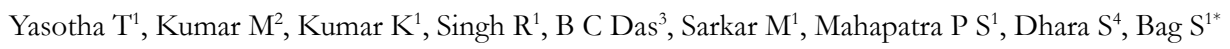

${ }^{1}$ Reproductive Physiology Lab, Division of Physiology and Climatology, Indian Veterinary Research Institute, Izatnagar, Bareilly, India. ${ }^{2}$ Present Address: Department of Veterinary Physiology and Biochemistry Banaras Hindu University, Varanasi, UP, India.

${ }^{3}$ ERS-IVRI, Kolkata, Belgachia, West Bengal, India.

${ }^{4}$ Veterinary Biotechnology Division, Indian Veterinary Research Institute, Izatnagar, Bareilly, UP, India.

\title{
Abstract
}

Induced pluripotent stem cells (iPSCs) have numerous applications in livestock to improve production traits, disease resistance, biopharming, conservation of germplasm, disease modeling, regenerative medicine etc. Here, we have described the derivation of iPSCs from buffalo fetal fibroblasts (BuiPSCs) by lentivirus based transduction of mouse derived pluripotency marker genes Oct4, Sox2, Klf4 and c-Myc. The BuiPSCs showed typical buffalo embryonic stem cells like colony morphology which were alkaline phosphatase (AP) positive and expressed pluripotency markers Oct4, Nanog, SOX2, KLF4, FoxD3 and SSEA1, TRA-1-60, TRA-1-81. The cells were carrying normal karyotype and were able to differentiate into cell of all three germ layers in vitro. The BuiPSCs could be propagated beyond $20^{\text {th }}$ passages. To the best of our knowledge, this is the first report on generation of buiPSCs in domestic water buffalo (Bubalus bubalis) using mouse derived transcription factors and the reprogrammed cells could self renew more than $20^{\text {th }}$ passage.

Keywords: Buffalo; Fetal Fibroblast; iPS Cells; Lenti Virus Vector; Mouse Derived Transcription Factors.

\section{Introduction}

Since the discovery of embryonic stem cells (ESCs) in mouse [1], stem cells technology has been envisioned to revolutionize livestock industry. Because ESCs are pluripotent, has remarkable plasticity and a single ESC can divide to form unlimited number of stem cells, they can be manipulated in Petri dish for wide range of applications including production of transgenic and cloned animal, generation of gamates, drug testing etc. However, in spite of considerable efforts, derivation of proven ESCs line in farm animals has so far been elusive $[2,3]$. The induced pluripotent stem cell (iPSCs) technology first described in 2006 [4] has revolutionized the stem cell research arena by providing another source of pluripotent stem cells even from each individual surpassing the constraint of availability of embryos and other issues. Surprisingly it was observed that the iPSCs resembled ESCs in cell morphology, expression of surface markers, telomerase activity, teratoma formation, gene expression, DNA methylation, formation of chimera etc [4] and thus iPSCs have been designated an alterna- tive to ESCs. The success of this technology has been proved by generation of iPSCs in human [5], rat $[6,7]$, non-human primates [8], pig [9], canine [10], cattle [11], sheep [12], hircine [13], equine [14] etc. Tremendous progress in iPSC technology within a very short period of time has emphasized its promising applications in regenerative medicine, "disease-in-a-dish" modeling, drug and toxicity screening, custom tailored therapeutics, transgenesis and for studying the developmental biology. Recently, preclinical studies has been successfully done for treating retina injury in pigs using pig iPSCs [15], cardiovascular disease in dog using dog iPSCs [16] and myocardial infarction in pigs using human iPSCs [17].

India is home to more than $50 \%$ of the buffalo (Bubalus bubalis) population of the world. It is also found in other south East Asian countries and commonly used for milk, meat and draught purpose. Buffalo iPSCs can be an alternative to buffalo ESC and can play a role in generation of improvement of milk production, growth rate, carcass composition, diseases resistance, reproductive performance, generation of gametes, conservation of germ

\footnotetext{
*Corresponding Author:

Bag Sadhan

Reproductive Physiology Lab, Division of Physiology and Climatology, Indian Veterinary Research Institute, Izatnagar, Bareilly, UP-243122, India.
}

E-mail: bag658@gmail.com

Received: May 05, 2016

Accepted: June 22, 2016

Published: June 24, 2016

Citation: Bag S, et al., (2016) Generation and characterization of induced pluripotent stem cells in domestic Asian water buffalo (Bubalus bubalis). Int J Stem Cell Res Transplant. 04(5), 182-189. doi: http://dx.doi.org/10.19070/2328-3548-1600030

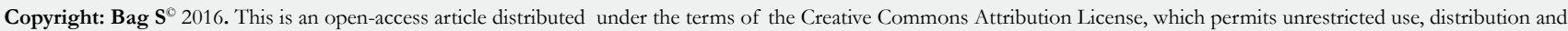
reproduction in any medium, provided the original author and source are credited. 
plasm etc. Research conducted so far indicates that derivation of pluripotent ESCs in buffalo either from early stage embryos or from blastocyst are limited and the success rate has been very low $[18,19]$. Therefore, iPSCs technology can be used for deriving pluripotent stem cells in this species. Recently, attempt has been made to derive iPSCs in buffalo using proteins of buffalo defined transcription factors, however, the cells could not be propagated beyond $10^{\text {th }}$ passage [20]. In the present study, we have generated buffalo iPSCs using mouse derived transcription factors (OKSM) which could be propagated beyond $20^{\text {th }}$ passages. The buffalo fetal skin fibroblast cells were transfected with lentivirus particle carrying the pluripotent genes and the colonies developed were mechanically propagated, characterized for expression of pluripotent markers, chromosomal integrity and ability to form three germ layer specific cells.

\section{Material and Methods}

\section{Ethics statement}

The entire procedure of collection of buffalo fetus from local large animal slaughter house and it's processing to obtain skin fibroblast cells in lab, was approved by the Animal Ethics Committee of Indian Veterinary Research Institute, India.

\section{Preparation buffalo fetal skin fibroblast cells (BFF)}

Buffalo fetuses of about 80 days of gestation were collected from the local large animal slaughter house, Bareilly and were transported in ice to the laboratory. The fetuses were washed thoroughly with PBS and all the appendages including head were removed, followed by washing again with PBS. The fetal skin was gently removed and minced into small pieces using BP blade and scissors. The skin explants were collected in fibroblast media (FM) containing knock out DMEM (Invitrogen), 10\% FBS (Gibco), 1mM L-glutamine (Gibco), 1\% Non essential amino acids (Gibco) and $0.5 \%$ Penicillin- Streptomycin (Gibco) as a suspension, centrifuged twice at $1000 \mathrm{rpm}$ for 5 minutes and the pellet containing explants was cultured in FM for harvesting fibroblast cells. The culture plates were treated with $0.05 \%$ trypsin (Gibco) and the dispersed cells were subsequently passaged in FM.

\section{Plasmid preparation and production of Lentivirus}

pLentG-KOSM plasmid vector (Cell Biolabs) in which the mouse transcription factors (OKSM) are in-frame fused into a single open reading frame (ORF) via self-cleaving $2 \mathrm{~A}$ peptides followed by IRES-GFP as a reporter for viral transduction was procured commercially in bacterial glycerol stock. The bacteria were grown in LB broth and plasmid DNA was isolated from the bacteria using mini and maxi prep culture kit (MDI) as per the manufacturer's instruction. The $293 \mathrm{~T}$ cells were plated in $35 \mathrm{~mm}$ dishes at a concentration of $1 \times 10^{5}$ and incubated at $37^{\circ} \mathrm{C}$ and $5 \% \mathrm{CO}_{2}$ for overnight. About $1 \times 10^{5}$, number of $293 \mathrm{~T}$ cells were plated in $35 \mathrm{~mm}$ tissue culture dishes and incubated at $37^{\circ} \mathrm{C}$ and $5 \%$ $\mathrm{CO}_{2}$ for overnight. The cells were then transfected with a mixture of vectors containing $2 \mu \mathrm{g}$ of pLentG KOSM, $0.7 \mu \mathrm{g}$ each of pRSV-Rev packaging vector, pCMV-VSV-G envelope vector as well as $\mathrm{pCgpV}$ packaging vector (Cell Biolabs) using Lipofectamine ${ }^{\mathrm{TM}}$ Plus (Invitrogen) as a transfection reagent following the manufacturer's instruction. Briefly, The viral supernatant was harvested after every 12 hours from 36 to 72 hours post transfection and stored at $4^{\circ} \mathrm{C}$ over the collection period. The lentivirus supernatant were pooled, and centrifuged at $1500 \mathrm{rpm}$ for $5 \mathrm{~min}$ utes to remove the cell debris, filtered in $0.22 \mu \mathrm{m}$ filter and stored at $-80^{\circ} \mathrm{C}$ in aliquots.

\section{Estimation of lentiviral titer}

To ensure that the psuedoviral medium is viable and to control the number of copies of integrated viral constructs per target cell, the lenti viral titer was estimated by Quick Titer ${ }^{\mathrm{TM}}$ Lentivirus Titer Kit (Cell Biolabs, Vat No VPK-107). The viral titer estimates were $8 \times 10^{7}$ lentiviral particles $/ \mathrm{ml}$. The stocks were frozen stored and used for transductions of fibroblast cells after thawing.

\section{Transduction of BFF}

One day before transduction, BFF of 3rd passage were seeded in a six well plate at a concentration of $2 \times 10^{4}$ cells/well in FM. Lentivirus supernatant $(2 \mathrm{ml})$ with ViraDuctin ${ }^{\mathrm{TM}}$ Lentivirus Transduction Reagent (Cell Biolabs) were added in each well as per the manufacturer's instruction. This was equivalent to approximately $16 \times 10^{7}$ viral particles per 20000 cells. After 48 hrs of viral transduction, FM was replaced with buffalo ESC media containing knock out DMEM, 20\% FBS, $1 \mathrm{mM}$ L-glutamine, $0.1 \mathrm{mM} \beta$ mercaptoethanol, $1 \%$ non essential amino acids, $0.5 \%$ penicillinstreptomycin, 10ng/ml bFGF (Millipore) and $4 \mathrm{ng} / \mathrm{ml}$ human LIF (Millipore). The transducted cells were monitored daily and ESC media was changed regularly. The cells were subcultured in $90 \mathrm{~mm}$ tissue culture dish following $90 \%$ confluence. The putative iPSC colonies were picked up and subcultured mechanically on BFF monolayer which was inactivated using mitomycin $\mathrm{C}$ as described earlier [21]. The same process was repeated for further propagation of buiPSC colonies. The detail time line for reprogramming of BFF has been presented in Figure $1 \& 2$.

\section{Alkaline phosphatase (AP) staining}

The buiPSC like colonies were stained for alkaline phosphatase (AP) as per the earlier described method [22]. Briefly, the culture plates were rinsed twice in $1 \mathrm{X}$ PBS ( $\mathrm{pH} 7.4)$ and fixed in $4 \%$ paraformaldehyde in $1 \mathrm{X}$ PBS for $15 \mathrm{~min}$ at room temperature. The fixed cells were washed twice with distilled water, stained with 0.5 $\mathrm{mg} / \mathrm{ml}$ naphthol AS-MX phosphate (Sigma) and $1 \mathrm{mg} / \mathrm{ml} \mathrm{FAST}$ RED TR salt (Sigma) in $100 \mathrm{mM}$ tris buffer ( $\mathrm{pH} \mathrm{8.2)} \mathrm{for} 4 \mathrm{~h}$ at room temperature. The staining was stopped by washing the cells in distilled water and the cells were observed under microscope for AP activity.

\section{In vitro differentiation}

The differentiation ability of buiPSC cells were examined by hanging drop culture. Briefly, a single cell suspension of iPSCs $\left(2.5 \times 10^{4}\right.$ cells $\left./ \mathrm{ml}\right)$ were prepared in differentiation media consisting of IMDM (Gibco) supplemented with $20 \%$ fetal calf serum, $1 \%$ non-essential amino acids, $2 \mathrm{mmol} / 1 \mathrm{~L}$-glutamine, and $100 \mu \mathrm{mol} / 1 \beta$-ME. From this cell suspension, $20 \mu \mathrm{l}$ was pipetted on to the lid of a tissue culture dish and then inverted over its bottom dish containing $5 \mathrm{ml}$ phosphate-buffered saline. On day 3 , the embryo bodies (EBs) was transferred on gelatin coated coverslip in 6 well tissue culture dishes and grown up to day 11, with 
Figure 1. Time line for reprogramming of buffalo fetal skin fibroblast.

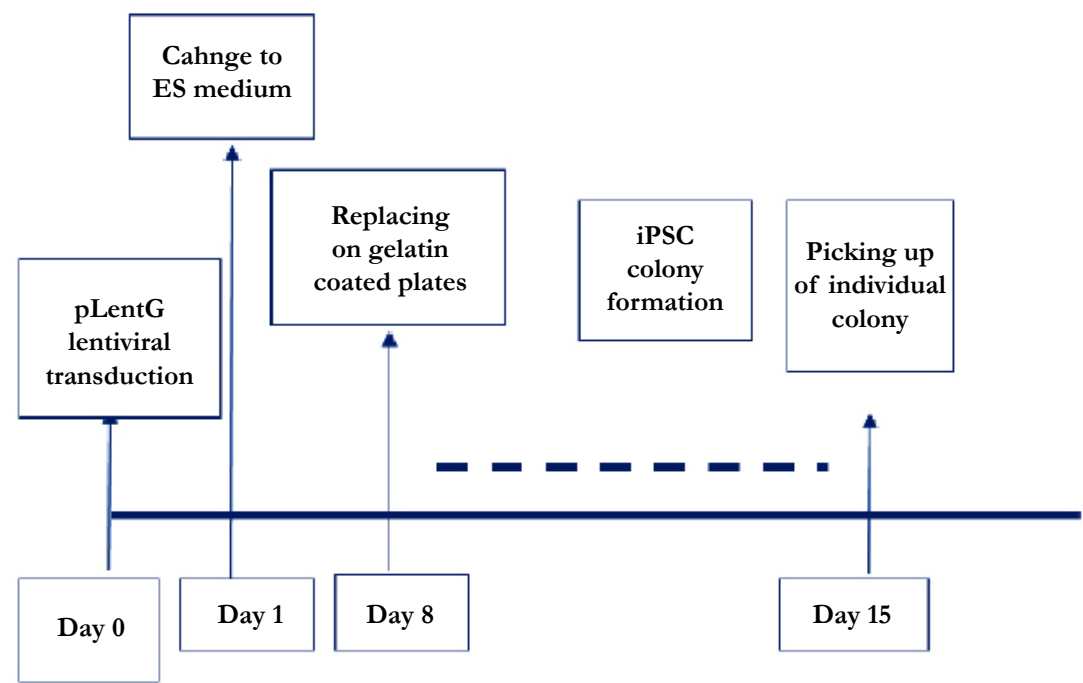

Figure 2. Generation of BuiPSC. (A) A $13.0 \mathrm{~kb}$ polycystronic lentivirus with mouse defined pluripotent genes (OSKM) was used to reprogram buffalo fetal skin fibroblast, (B)293T cells were used for lentivirus production, (C) buffalo fetal skin fibroblast cells, (D) buffalo fibroblast with lentivirus particle having pLentG KOSM, (E) Transducted cells after 48 hrs, (F) Transducted cells after 48 hrs showing GFP expression, (G -H) Small colony after day 4 of transduction, (I-J) iPSC like colonies after day20th of transduction, (K,L) buiPSC colony after first passage (P1), (M) buiPSC colonies at passage Six (P6), (N). BuiPSC colonies at passage 12, (O) BuiPSC in 16th passage (P) No expression of transgene as indicated by GFP expression at $\mathrm{P}^{6}{ }^{\text {th }}$.(Q) P24th Passage. Scale bar $100 \mu \mathrm{m}$
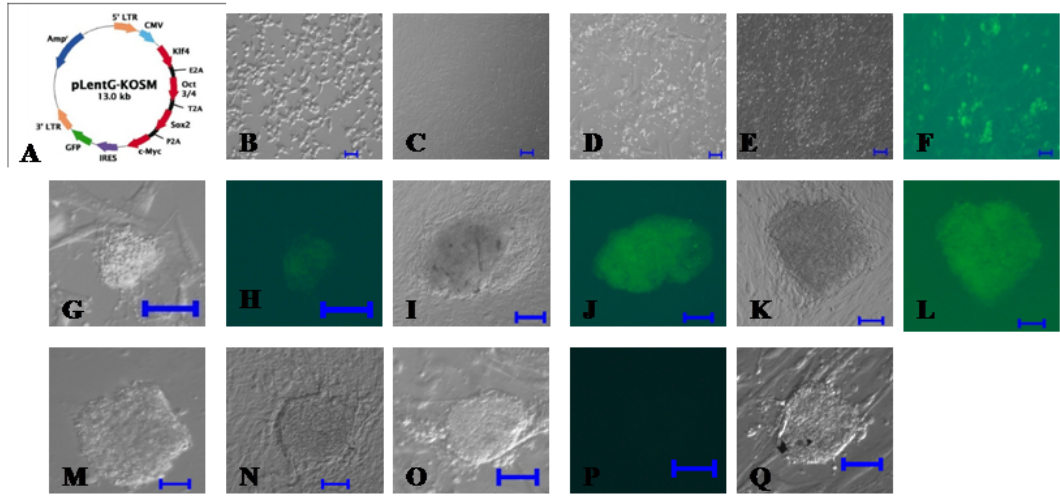

periodical changing of the media. For studying the expression of genes indicating the formation of cell of three germ layers, 8-10 numbers of EBs were collected on different days (EB-D0, EBD3, EB-D7, EB-D9, EB-D11) for isolation of total RNA. On day 9, the EBs on cover slip was also processed for immunocytochemistry using ectoderm (G-FAP), endoderm (AFP) and mesodermal (alpha SMA) cells specific antibody.

\section{Immunocytochemistry}

Immunocytochemistry was done as per the methods of $\mathrm{Na}$ tional Institutes of Health, resource for stem cell research, USA. Briefly, cells were fixed with $4 \%$ paraformaldehyde, blocked with $5 \%$ BSA in PBS, then incubated with the following primary antibodies overnight at $4^{\circ} \mathrm{C}$ : mouse monoclonal anti-TRA-1-60 and TRA-1-81, Oct4, Nanong, SSEA1 (Santa Cruz Biotechnology), G-FAP (Sigma), AFP (Sigma) and alpha SMA (Sigma). The cells were then immunostained with appropriate Alexa FluorR594 conjugated secondary antibodies (Life Technology) for $2 \mathrm{~h}$. The negative control was performed following the entire procedure, except adding primary antibodies.
Molecular characterization - RNA extraction and real timepolymerase chain reaction

For gene expression analysis, 5-6 number of BuiPSCs colonies of different passages (Po, P5, P10) as well as 8-10 numbers of EBs of each time interval of differentiation were used. The total RNA was isolated from all the samples using Quick-RNA ${ }^{\text {TM }}$ MicroPrep kit (Zymo Research Kit) as per manufacturer's protocol and The cDNA was synthesized using fixed amount of isolated RNA by using iScript select cDNA Synthesis kit (Biorad). Amplification of genes was performed using gene-specific primers (Table 1) and Eva Green supermix (Biorad, USA) as per manufacturer's instructions. The PCR reaction included an initial denaturation at $95^{\circ} \mathrm{C}$ for 3 min followed by 40 cycles of denaturation at $95^{\circ} \mathrm{C}$ for $5 \mathrm{~s}$, annealing at $54^{\circ} \mathrm{C}(\mathrm{Klf} 4), 55^{\circ} \mathrm{C}(\mathrm{Oct} 4), 56^{\circ} \mathrm{C}(\mathrm{Foxd} 3), 60^{\circ} \mathrm{C}(\beta$-actin, Nanog, Sox 2, C-myc, BMP4 and CDX2) and $65^{\circ} \mathrm{C}$ (Nestin) for $15 \mathrm{~s}$. To ensure the specificity of target amplification, melting curves and agarose $(2 \%)$ gel electrophoresis of the PCR reactions were performed. The relative mRNA expression of genes was calculated using the $2^{-\Delta \Delta C \mathrm{~T}}$ method (Livak and Schmittgen, 2001) 
Table 1. Real Time PCR was performed with gene specific primers as mentioned below:

\begin{tabular}{|c|c|c|c|c|}
\hline S.N & Gene & Primer & Product (bp) & Reference \\
\hline 1 & $\beta$-actin & $\begin{array}{l}\text { F 5'-tcatcaccatcggcaatg-3' } \\
\text { R 5'-ccaatccacacggagtac-3' }\end{array}$ & 286 & AY141970 \\
\hline 2 & Oct-4 & $\begin{array}{l}\text { F 5'-caatttgccaagctcctaaag-3' } \\
\text { R 5'-gcctctcactcggttctc-3' }\end{array}$ & 288 & NM_174580 \\
\hline 3 & Nanog & $\begin{array}{l}\text { F 5'-gtcccggtcaagaaacaaaa-3' } \\
\text { R 5'-tgcatttgctggagactgag-3' }\end{array}$ & 107 & [51] \\
\hline 4 & Sox 2 & $\begin{array}{l}\text { F 5'-cggcaaccagaagaacag-3' } \\
\text { R 5'-cggcagtgtgtacttatcc-3' }\end{array}$ & 292 & NM_001105463 \\
\hline 5 & Klf4 & $\begin{array}{l}\text { F 5'-gaactgaccaggcactac-3' } \\
\text { R 5'-ctgattatccattcacaagttg-3' }\end{array}$ & 271 & NM_001105385 \\
\hline 6 & Foxd3 & $\begin{array}{l}\text { F 5'-agcaagcccaagaatagc-3' } \\
\text { R 5'-tccagggtccagtagttg-3' }\end{array}$ & 257 & XM_610898 \\
\hline 7 & C-myc & $\begin{array}{l}\text { F 5'-tttgctcttcgtgaccag-3' } \\
\text { R 5'-tgcccaaagttccatttg-3' }\end{array}$ & 400 & Z68501.1 \\
\hline 8 & Nestin & $\begin{array}{l}\text { F-5'-aacgctgagtcattgagaac-3' } \\
\text { R-5'-cactgcctcctggtcttc-3' }\end{array}$ & 276 & NM_001206591 \\
\hline 9 & BMP4 & $\begin{array}{l}\text { F-caggctaccaggcattctac-3' } \\
\text { R-accaccttgtcatactcatcc-3' }\end{array}$ & 190 & BC105344 \\
\hline 10 & CDX2 & $\begin{array}{l}\text { F-5'-aacctgtgcgagtggatg-3' } \\
\text { R-5'-ctgttgctgctgctgttg-3' }\end{array}$ & 276 & NM_001206299 \\
\hline
\end{tabular}

and the results were expressed as a fold change in expression over the control. The samples of at least three experiments were analyzed for gene expression studies.

\section{Results}

The chronology of BuiPSC generation has been presented in Figure 1 and 2. The Lentivirus virus particles having polycystronic vector (Figure 2A) was produced in 293T cell (Figure 2B). The BFF cells $\left(2 \times 10^{4}\right.$ cells/well) (Figure $\left.2 \mathrm{C}\right)$ in a six well culture plate were transducted with pLentG lentiviral vector on day 0 (Figure 2D) and the GFP expression was visible witin 2-3 days post transduction (Figure. 2E,F), which indicated the successful integeration of transgenes into the host genome. Small clumps of cells were observed on day 4-8 (Figure. 2G, H); however, the confluent transducted cells were further replated in $90 \mathrm{~mm}$ dishes to avoid the interference in the formation of colonies due to high number of cells. On day 15, morphologically uniform compact, flattened AP positive colonies had emerged (Figure. 2I, J). From day 15 to day 25 post transduction, numerous well defined colonies resembling buffalo ESC colony morphology were formed. Out of these, 18 colonies were picked up and sub cultured by mechanical passaging on inactivated BFF feeder cells. They grew rapidly and within 3-4 days, well defined secondary colonies had appeared (Figure. 2K, L) which were subsequently passaged following the same procedure (Figure. $2 \mathrm{M}, \mathrm{N}, \mathrm{O}, \mathrm{P}, \mathrm{Q})$. The newly formed colonies on subsequent passages maintained buffalo ESC morphology which were propagated beyond $20^{\text {th }}$ passages (Data not shown). An average 24 numbers of well defined colonies were formed out of 20,000 transducted cells with a reprogramming efficiency of $0.12 \%$. Initially, the GFP expression in colonies were strong but started declining at passage 6 to 7 and no expression was observed at $12^{\text {th }}$ passage indicating probable silencing of transgene (Figure. $3 \mathrm{~A}-\mathrm{E}$ ). The colonies had well de- fined borders and were positive for alkaline phosphatase activity (Figure 4A). Using RTPCR, we could detect robust expression of pluripotentency marker genes Oct4, Sox2, Nanog, C-Myc, KLF4 and FoxD3 (Figure 4B) in passage P0, P5 and P10. Further, the colonies were strongly immunopositive for Oct4, Nanog, Sox2, SSEA1, TRA-1-60 and TRA-1-81 (Figure. 5A). When analyzed at passage 5 , during in vitro propagation, the colonies exhibited normal chromosome numbers (Figure. 5B). Further, the colonies readily formed $\mathrm{EBs}$ following in vitro differentiation (Figure. 6A, B). RTPCR and immunocytochemistry analysis revealed the expression of lineage-specific genes representing the three germ layers: endoderm-cdx2 ( $\alpha$-feto-protein), ectoderm-Nestin and mesoderm-BMP4 (Figure. 6CDEF). After proper characterization, the colonies generated have been named BuiPSCs.

\section{Discussion}

In the present study, we have generated BuiPSCs by reprogramming fetal skin fibroblast using mouse derived plurpotentcy factors. The cell colonies aroused from transducted fibroblast had well defined morphology resembling buffalo ESC [18, 19] and expressed various pluripotency markers qualifying them as pluripotent stem cells. The lentivirus transfected cells showed expression of GFP within 48-72h which indicated successful integration of transgenes into fibroblast genome. Small colonies appeared as early as on day 4-8, but it took about 15-25 days to get alkaline phosphatase positive numerous compact large colonies resembling buffalo ESC morphology. In three replicates, an average of 24 colonies were observed providing a comparatively higher reprogramming efficiency. In most of the species, similar trend has been observed and about 10-25 days were the usual time of post transfection when the colonies attained the size for propagation. AP positive compact colonies of incorporate sheep iPSCs were observed after about 13 days post transduction of fibroblast with 
Figure 3. Silencing of transgene in BuiPSC. (A, B) representing GFP expression in passage 3, (C) Reducing expression of GFP in passage 7 and no expression was observed at passage 12 . Scale bar $100 \mu \mathrm{m}$.
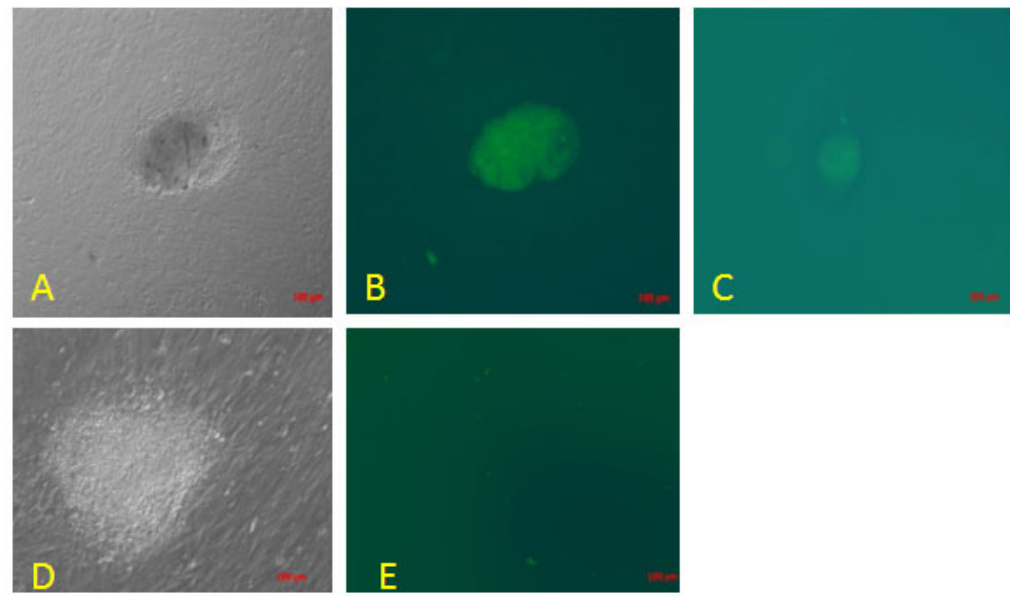

Figure 4. Characterisation of BuiPSC. (A) AP staining, (B) Expression of pluripotent markers genes in different passages of BuiPSC.
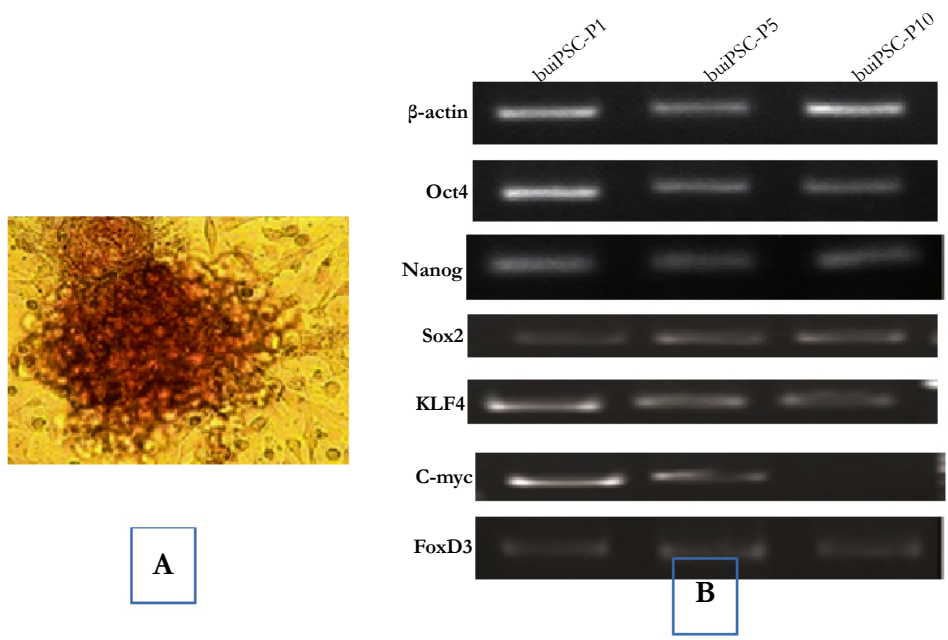

Figure 5. Characterisation of BuiPSC. (A) Immunoflourescence staining showing expression of pluripotent markers in BuiPSC (Scale bar $100 \mu \mathrm{m})$. B. BuiPSC showing normal Karyotype.

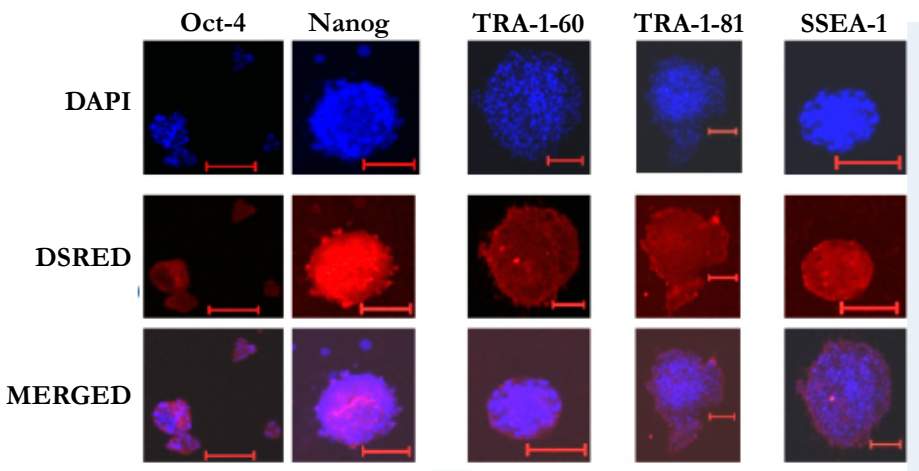

A

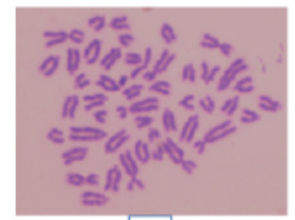

B 
Figure 6. In vitro differentiation of BuiPSC. (A) BuiPSC colony (B) Embryobodies formed after 72 hrs in differentiation medium (C) Expression of lineage specific gene expression in BuiPSC derived embryod bodies, buffalo fibroblast and BuiPSC: Nestin, (ectoderm), cdX2 (Endoderm) and BMP4 (mesoderm). D, E and F represents the neuronal cells (G-fap), Endodermal cells (AFP) and Mesodermal cells (alpha SMA) (Scale bar 100 $\mu \mathrm{m})$.

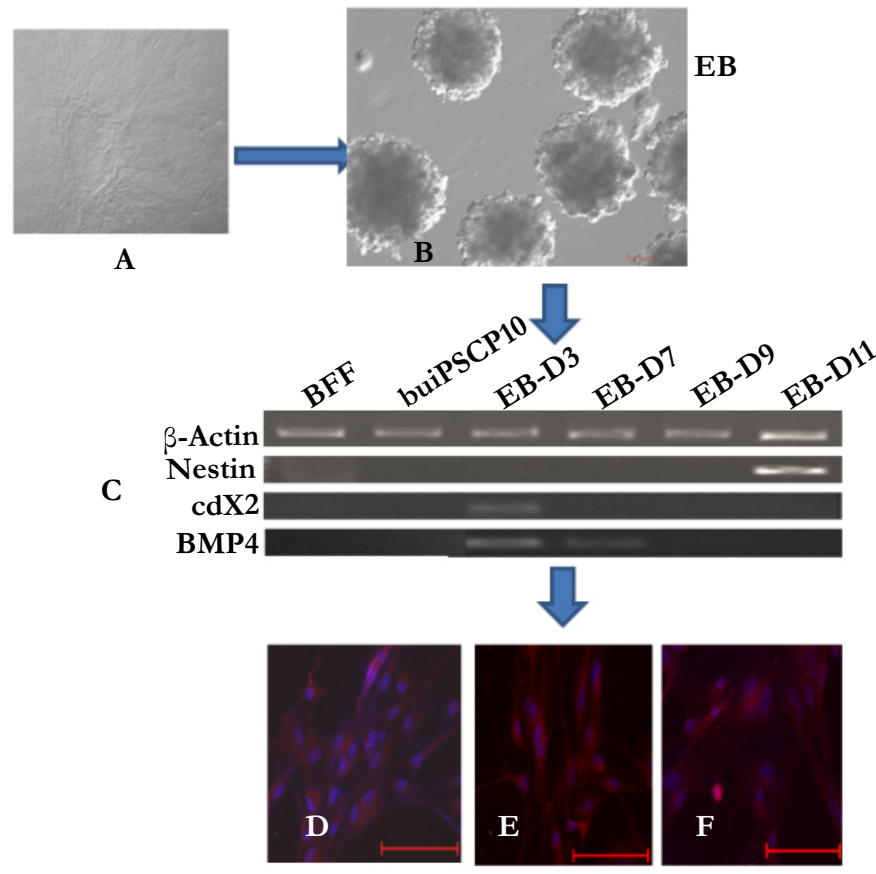

very low reprogramming efficiency $(0.001875 \%)$ [3]. In case of bovine iPSCs, small colonies were formed on day 4 of transduction and colonies were ready for picked up as early as on day 7 [23]. Again the reprogramming efficiency recorded was only $0.0002 \%$. Further, they reported that repeated transfection increased the reprogramming efficiency $(0.0007 \%)$. In equine iPSCs generation, it took 17-18 days post-transfection, when many clearly defined colonies were formed [14] with a reprogramming efficiency of $0.028 \%$ based on the transfected (GFP+) cells which was comparable to those obtained when reprogramming human and mouse fibroblasts with the same transfection system [24]. In the present study, the BFF was transfected only once for $48 \mathrm{~h}$ which may be the reason for taking longer days for development of well defined colonies. However, the reprogramming efficiency was $0.048 \%$ which was comparable with equine iPSC generation [14]. However, it has been reported that the reprogramming efficiency can be enhanced by using small molecules like valproic acid, suberoylanilide hydroxamic acid (SAHA) and trichostatin A (TSA) [25], p53 siRNA [26] and vitamin C [27]. It is assumed that transcription factor of same species would be better for reprogramming, but in the present study, mouse defined transcription factor was able to generate buiPSCs. In several studies, mouse defined factors have already been shown to reprogram fibroblasts of pig [7, 9], sheep [28], horse [11] etc. These results indicated that defined factors related to iPSCs are highly conserved among species. Silencing of transgenes is important for potential clinical applications of iPSCs. Although transgenes introduced by lentiviral vectors are generally not silenced or poorly silenced [29], integrated transgene of pLentG KSOM was silenced 12 days after transduction and no GFP could be observed through-out subsequent culturing. In the present study, GFP expression was not detectable at $12^{\text {th }}$ passage [30]. Whereas, it is reported that the EGFP expression in bovine iPSCs was fully absent only after $20^{\text {th }}$ passage [23]. In vitro embryo body formation and invivo teratoma formations are the two key factors of successful generation of pluripotent stem cells. In the present study, the BuiPSCs readily formed well defined embryoid bodies which on differentiation, formed cells of three germ layers. The iPSCs derived from mouse, human, sheep, bovine, equine etc haven all been shown to form embryo bodies and teratoma expressing the cells of ectoderm, endoderm and mesoderm [4, $14,28,31,32]$. In the present study, only four transcription factors viz oct4, Sox2, KLF4 and c-myc were able to generate buiPSC. In earlier studies involving different species, iPSCs have been generated by different combinations of transcription factors. For example, only Nanog and Lin28 were able to generate iPSCs from the IMR90 fetal fibroblast line and post-natal fibroblasts from human newborn foreskin [31]. Other experiments which resulted in generation of iPSCs in different species have used combination of Oct4, Sox2, Lin28 and Nanog [33], Oct4 with either Klf4 or c-MYC [34], Oct4, Sox2, Nanog [35], Oct4 and Sox2 [25, 36], Oct4 and Klf4 [37], or even by using only Oct4 [38]. In cattle it has been shown that in addition to Yamanaka factors, nanog is necessary for generating iPSC [39]. We assumed that nanog in addition of KOSM may improve the reprogramming efficiency of buffalo fibroblast cells. We have used polycystronic lentivirus vector produced in the laboratory for transduction of buffalo fibroblast cells. Lentiviruses are a subclass of retroviruses capable of transducing a wide range of both dividing and non-dividing cells. Various reports suggest that cellular reprogramming is best achieved when lentiviral transduction is done $[31,40]$. However, successful reprogramming have been achieved by using virus back bone free plasmids carrying the reprogramming factors, piggyBac (PB) transposon gene-delivery system, non-DNA approach using small molecules or chemicals, delivering proteins of transcription factors and miRNA etc [15, 41-44]. Recently reprogramming of fetal fibroblast of buffalo and goat has been attempted using egg extract of poultry $[45,46]$. Similarly reprogramming of adult cells have been tried using oocyte extracts in an attempt to 
generate iPSC without foreign DNA [47]. In the present study, a single polycystronic vector was used for reprogramming of fibroblast cells. In several studies, multiple individual viral vectors have been used for delivering each of the transcription factors that resulted in high genomic integration. However, the number of viruses necessary to reprogram somatic cells had been reduced by delivering reprogramming factors in a single virus using $2 \mathrm{~A}$ "self-cleaving" peptides, which support efficient polycistronic expression from a single promoter, thus increasing reprogramming efficiency $[48,49]$.

Pluripotent stem cell generation in domestic ungulates has so far been very difficult [50]. As stated earlier, derivation of pluripotent ESCs in buffalo either from early stage embryos or from blastocyst are limited and the success rate has been very low $[18,19]$. Therefore, iPSCs technology can be used for deriving pluripotent stem cells in this species. Unfortunately, the initial attempt to produce buffalo iPSCs has been partially successful as the reprogrammed cells could be propagated only upto $10^{\text {th }}$ passage [21]. Therefore, our study is important as we could propagate the cells beyond the numbers of passages achieved by Deng group. This better progression may be due to use of poly cystronic vectors consisting of pluripotent genes and delivered through lentivirus vector.

Application of stem cell technology in improving animal production is a promising area. As stated earlier, despite more than two decades of effort, establishment of pluripotent embryonic stem cells from ungulates has remained an elusive goal. Recently derivation of buffalo ESCs has been reported but the success rate has been very low. Therefore, buffalo iPSCs would be the alternative to ESC. The advantage of this technology is that, quality pluripotent cells can be generated from individual genetically superior animal and these cells not only be used for animal cloning and transgenesis, but gametes can also be produced in vitro ensuring propagation of the superior germ plasm. Further, if a high producing buffalo male or female fails to produce gametes due to toxicity, radiation exposure or failure of ejaculation due to permanent disability, iPSCs can be generated from such quality animal for further propagation. Apart from these, such cells would also open up possibilities to use the buffalo as an excellent pre-clinical model for future human stem cell-based therapies. However, virus back bone free iPSCs need to be generated for their large scale application in future.

\section{Conclusion}

In the present study, we report on successful derivation of iPSC cells from buffalo fetal fibroblasts. The BuiPSCs displayed pluripotent characteristics as evidenced by expression of key pluripotency markers, alkaline phosphatase activity, and the formation of cells representing all the three embryonic germ layers.

\section{Acknowledgements}

This study was financially by Department of Biotechnology and NAIP, ICAR, New Delhi, India.

\section{References}

[1]. Evans MJ, Kaufman M.H (1981) Establishment in culture of pluripotential cells from mouse embryos. Nature 292: 154-156.

[2]. Talbot NC, Blomberg LA (2008) The pursuit of ES cell lines of domesticated ungulates. Stem Cell Rev 4(3): 235-254.

[3]. Liu H, Zhu F, Yong J, Zhang P, Hou P, et al., (2008) Generation of induced pluripotent stem cells from adult rhesus monkey fibroblast. Cell Stem Cell 3(6): $587-590$

[4]. Takahashi K, Yamanaka S (2006) Induction of pluripotent stem cells from mouse embryonic and adult fibroblast cultures by defined factors. Cell 126(4): 663-676.

[5]. Takahashi K, Tanabe K, Ohnuki M, Narita M, Ichisaka T, et al., (2007) Induction of pluripotent stem cells from adult human fibroblasts by defined factors. Cell 131(5): 861-872.

[6]. Liao J, Cui C, Chen S, Ren J, Chen J, et al., (2009) Generation of induced pluripotent stem cell lines from adult rat cells. Cell Stem Cell 4(1): 11-15.

[7]. Ezashi T, Telugu BP, Alexenko AP, Sachdev S, Sinha S, et al., (2009) Derivation of induced pluripotent stem cells from pig somatic cells. Proc Natl Acad Sci 106(27): 10993-10998.

[8]. Wu Y, Zhang Y, Mishra A, Tardis SD, Hornsby PJ (2010) Generation of induced pluripotent stem cells from newborn marmoset skin fibroblasts. Stem Cell Res 4(3): 180-188.

[9]. Wu Z, Chen J, Ren J, Bao L, Liao J, et al., (2009) Generation of pig induced pluripotent stem cells with a drug-inducible system. J Mol Cell Biol 1(1): 46-54.

[10]. Shimada H, Nakada A, Hashimoto Y, Shigeno K, Shionoya Y, et al., (2010) Generation of canine induced pluripotent stem cells by retroviral transduction and chemical inhibitors. Mol Reprod Dev 77(1): 2 .

[11]. Huseyin S, Jun L, Luis F, Malaver O, Mei LL, et al., (2011) NANOG is a key factor for induction of pluripotency in bovine adult fibroblasts. J Anim Sci 89(9): 2708-2716.

[12]. Yang L, Ming C, Andrew SL, Kehua Z, Dongjun L (2011) Reprogramming of sheep fibroblasts into pluripotency under a drug-inducible expression of mouse-derived defined factors. PLoS One 6(1): e15947.

[13]. Ren J, Pak Y, He L, Qian L, Gu, Y, et al., (2011) Generation of hircineinduced pluripotent stem cells by somatic cell reprogramming. Cell Res 21(5): 849-853.

[14]. Nagy K, Hoon KS, Puzheng Z, Simon L, Patrick V, et al., (2011) Induced Pluripotent Stem Cell Lines Derived from Equine Fibroblasts. Stem Cell $\operatorname{Rev} 7(3):$ 693-702.

[15]. Zhou L, Wang W, Liu Y, Castro JF, Ezashi T, et al., (2011) Differentiation of induced pluripotent stem cells of swine into rod photoreceptors and their integration into the retina. Stem Cells 29(6): 972-980.

[16]. Lee AS, Xu D, Plews JR, Nguyen PK, Nag D, et al., (2011) Preclinical derivation and imaging of autologously transplanted canine induced pluripotent stem cells. J Biol Chem 286(37): 32697-32704.

[17]. Templin C, Zweigerdt R, Schwanke K, Olmer R, Ghadri JR, et al., (2012) Transplantation and tracking of human-induced pluripotent stem cells in a pig model of myocardial infarction: Assessment of cell survival, engraftment, and distribution by hybrid single photon emission computed tomography/ computed tomography of sodium iodide symporter transgene expression. Circulation 126(4): 430-439.

[18]. Verma V, Gautam SK, Singh B, Manik RS, Palta P, et al., (2007) Isolation and characterization of embryonic stem cell-like cells from in vitro-produced buffalo (Bubalus bubalis) embryos. Mol Reprod Dev 74(4): 520-529.

[19]. Sharma R, George A, Kamble NM, Singh KP, Chauhan, MS, et al., (2011) Optimization of culture conditions to support long term self-renewal of buffalo (Bubalus bubalis) embryonic stem cell like cells. Cell Reprogram 13(6): 539-549.

[20]. Deng Y, Liu Q, Luo C, Chen S, Li X, et al., (2012) Generation of induced pluriopotent stem cells from buffalo (Bubalus bubalis) fetal fibroblasts with buffalo defined factors. Stem Cells Dev 21(13): 2485-2494.

[21]. Kumar A, Kumar K, Singh R, Puri G, Ranjan R, et al., (2012) Effect of mitotic inducers and retinoic acid blocker on expression of pluripotent genes in ES cells derived from early stage in vitro produced embryos in buffalo. In Vitro Cell Dev Bio-Animal 48(10): 625-632.

[22]. Moore K, Piedrahita JA (1997) The effects of human leukemia inhibitory factors (HLIF) and culture medium on in vitro differentiation of cultured porcine inner cell mass. In Vitro Cell Dev Biol Anim 33(1): 62-71.

[23]. Cao H, Yang P, Pu Y, Sun X, Yin H, et al., (2012) Characterization of bovine induced pluripotent stem cells by lentiviral transduction of reprogramming factor fusion proteins. Int J Biol Sci 8(4): 498-511.

[24]. Wang W, Lin C, Lu D, Ning Z, Cox T, et al., (2008) Chromosomal transposition of PiggyBac in mouse embryonic stem cells. Proc Natl Acad Sci U S A 105(27): 9290-9295.

[25]. Huangfu D, Osafune K, Maehr R, Guo W, Fijkelenboom A, et al., (2008) Induction of pluripotent stem cells by defined factors is greatly improved by small-molecule compounds. Nat. Biotechnol 26: 795-797. 
[26]. Hong H, Takahashi K, Ichisaka T, Aoi, T, Kanagawa M, et al., (2009) Suppression of induced pluripotent stem cell generation by the p53-p21 pathway. Nature 460(7259): 1132-1135.

[27]. Esteban MA, Xu J, Yang J, Peng M, Qin D, et al., (2009) Generation of induced pluripotent stem cell lines from Tibetan miniature pig. J Biol Chem 284(26): 17634-17640.

[28]. Bao L, He L, Chen J, Wu Z, Liao, J, et al., (2011) Reprogramming of ovine adult fibroblasts to pluripotency via drug-inducible expression of defined factors. Cell Res 21(4): 600-608.

[29]. Brambrink T, Forman R, Welstead GG, Lenger CJ, Wernig M, et al., (2008) Sequential expression of pluripotency markers during direct reprogramming of mouse somatic cells. Cell Stem Cells 2(2): 151-159.

[30]. Shao L, Feng W, Sun Y, Bai H, Liu J, et al., (2009) Generation of iPS cells using defined factors linked via the self-cleaving $2 \mathrm{~A}$ sequences in a single open gradient frame. Cell Res 19(3): 296-306.

[31]. Yu J, Vodyanik MA, Smuga OK, Antosiewicz BJ, Frane JL, et al., (2007) Induced pluripotent stem cell lines derived from human somatic cells. Science 318(5858): 1917-1920.

[32]. Han X, Han J, Ding F, Cao S, Lim SS, et al., (2011) Generation of induced pluripotent stem cells from bovine embryonic fibroblast cells. Cell Res 21(10): 1509-1512.

[33]. Haase A, Olmer R, Schwanke K, Wunderlich S, Merkert S, et al., (2009) Generation of induced pluripotent stem cells from human cord blood. Cell Stem Cell 5(4): 434-441.

[34]. Kim JB, Zaehres H, Wu G, Gentile L, Ko K, et al., (2008) Pluripotent stem cells induced from adult neural stem cells by reprogramming with two factors. Nature 454: 646-650.

[35]. Zhao HX, Li Y, Jin HF, Xie L, Liu C, et al., (2010) Rapid and efficient reprogramming of human amnion-derived cells into pluripotency by three factors OCT4/SOX2/NANOG. Differentiation 80(2-3): 123-129.

[36]. Giorgetti A, Montserrat N, Aasen T, Gonzalen F, Piza R, et al., (2009) Generation of induced pluripotent stem cells from human cord blood using OCT4 and SOX2. Cell Stem Cell 5(4): 353-357.

[37]. Tsai SY, Clavel C, Kim S, Ang YS, Grisanti L, et al., (2010) Oct4 and klf4 reprogram dermal papilla cells into induced pluripotent stem cells. Stem Cells 28(2): 221-228.

[38]. Kim JB, Greber B, Arau MJ, Meyer J, Park KI, et al., (2009) Direct reprogramming of human neural stem cells by OCT4. Nature 461: 649-643.

[39]. Sumer H, Liu J, Malaver LF, Lim ML, Khodadadi K, et al., (2011) NANOG is a key factor for induction of pluripotency in bovine adult fibroblasts. J Anim. Sci 89(9): 2708-2716.
[40]. Maherali N, Ahfeldt T, Rigamonti A, Utikal J, Cowan C, et al., (2008) A high-effi ciency system for the generation and study of human induced pluripotent stem cells. Cell Stem Cell 3(3): 340-345.

[41]. Okita K, Nakagawa M, Hyenjong H, Ichisaka T, Yamanaka S (2008) Generation of mouse induced pluripotent stem cells without viral vectors. Science 322(5903): 949-953.

[42]. Woltjen K, Michael IP, Mohseni P, Desai R, Mileikovsky M, et al., (2009) piggyBac transposition reprograms fibroblasts to induced pluripotent stem cells. Nature 458(7239): 766-770.

[43]. Yusa K, Rad R, Takeda J, Bradley A (2009) Generation of transgene-free in duced pluripotent mouse stem cells by the piggyBac transposon. Nat Methods 6(5): 363-369.

[44]. Lin SL, Chang DC, Lin CH, Ying SY, Leu D, et al., (2011) Regulation of somatic cell reprogramming through inducible mir-302 expression. Nucleic Acids Res 39(3): 1054-1065.

[45]. Bharadwaj P, Kumar K, Singh R, Puri G, Yasotha T, et al., (2013) Reprogramming of fetal cells by avian EE for generation of pluripotent stem cell like cells in caprine. Research in veterinary Science 95(2): 638-643.

[46]. Mahapatra PS, Bag S (2014) Reprogramming of buffalo (Bubalus bubalis) foetal fibroblasts with avian egg extract for generation of pluripotent stem cells. Research in Veterinary Science 96(2): 292-298.

[47]. Miyamoto K, Tsukiyama T, Yang Y, Li N, Minami M, et al., (2009) Cell free extracts from mammalian oocytes partially induce nuclear reprogramming in somatic cells. Biol Reprod 80(5): 935-943.

[48]. Carey BW, Markoulaki S, Hanna J, Saha K, Gao Q, et al., (2009) Reprogramming of murine and human somatic cells using a single polycistronic vector. Proc Natl Acad Sci 106(1): 157-162.

[49]. Chang CW, Lai, YS, Pawlik KM, Liu K, Sun CW, et al., (2009) Polycistronic lentiviral vector for "hit and run" reprogramming of adult skin fibroblasts to induced pluripotent stem cells. Stem Cells 27(5): 1042-1049.

[50]. Keefer CL, Pant D, Blomberg L, Talbot NC et al., (2007) Challenges and prospects for the establishment of embryonic stem cell lines of domesticated ungulates. Anim Reprod Sci 98(1-2): 147-168.

[51]. Pant D, Keefer CL (2009) Expression of pluripotency-related genes during bovine inner cell mass explants culture. Cloning and Stem cells 11(3): $355-365$. 